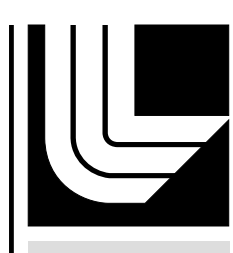

LAWRENCE LIVERM ORE N A TIO NAL LABORATORY

Size Distribution and Oxide Thickness of Uranium Micro-Spheres

W. J. Siekhaus, N. E. Teslich

August 1, 2013 
This document was prepared as an account of work sponsored by an agency of the United States government. Neither the United States government nor Lawrence Livermore National Security, LLC, nor any of their employees makes any warranty, expressed or implied, or assumes any legal liability or responsibility for the accuracy, completeness, or usefulness of any information, apparatus, product, or process disclosed, or represents that its use would not infringe privately owned rights. Reference herein to any specific commercial product, process, or service by trade name, trademark, manufacturer, or otherwise does not necessarily constitute or imply its endorsement, recommendation, or favoring by the United States government or Lawrence Livermore National Security, LLC. The views and opinions of authors expressed herein do not necessarily state or reflect those of the United States government or Lawrence Livermore National Security, LLC, and shall not be used for advertising or product endorsement purposes.

This work performed under the auspices of the U.S. Department of Energy by Lawrence Livermore National Laboratory under Contract DE-AC52-07NA27344. 


\title{
Size Distribution and Oxide Thickness of Uranium Micro-spheres.
}

\author{
Wigbert J. Siekhaus, Nick E. Teslich
}

This work performed under the auspices of the U.S. Department of Energy by Lawrence Livermore National Laboratory under Contract DE-AC52-07NA27344.

LLNL release number: LLNL-TR-641644

\begin{abstract}
Uranium microspheres were produced about twenty years ago and kept in a glove-box atmosphere. Their size distribution and surface roughness was analyzed at LLNL using a secondary electron microscope (SEM). They have a wide size distribution (from about 2 to about $30 \mu \mathrm{m}$ with a mean diameter of about $15 \mu \mathrm{m}$ ), and in addition show frequently clustering where 2 or more originally roughly spherical particles combine into a "dumbbell" shaped entities. To determine the thickness of their oxide layer they were sectioned using focused ion beam (FIB) etching. Oxide thickness varies from about $40 \mathrm{~nm}$ to 140 $\mathrm{nm}$. In addition, oxide "globs" of substantially larger thickness are attached to the perimeter of particles.
\end{abstract}

\section{Experimental.}

$7.5 \mathrm{~g}$ of uranium particles were shipped in a tube sealed with UHV Cajon VCR fittings (see figure 1).

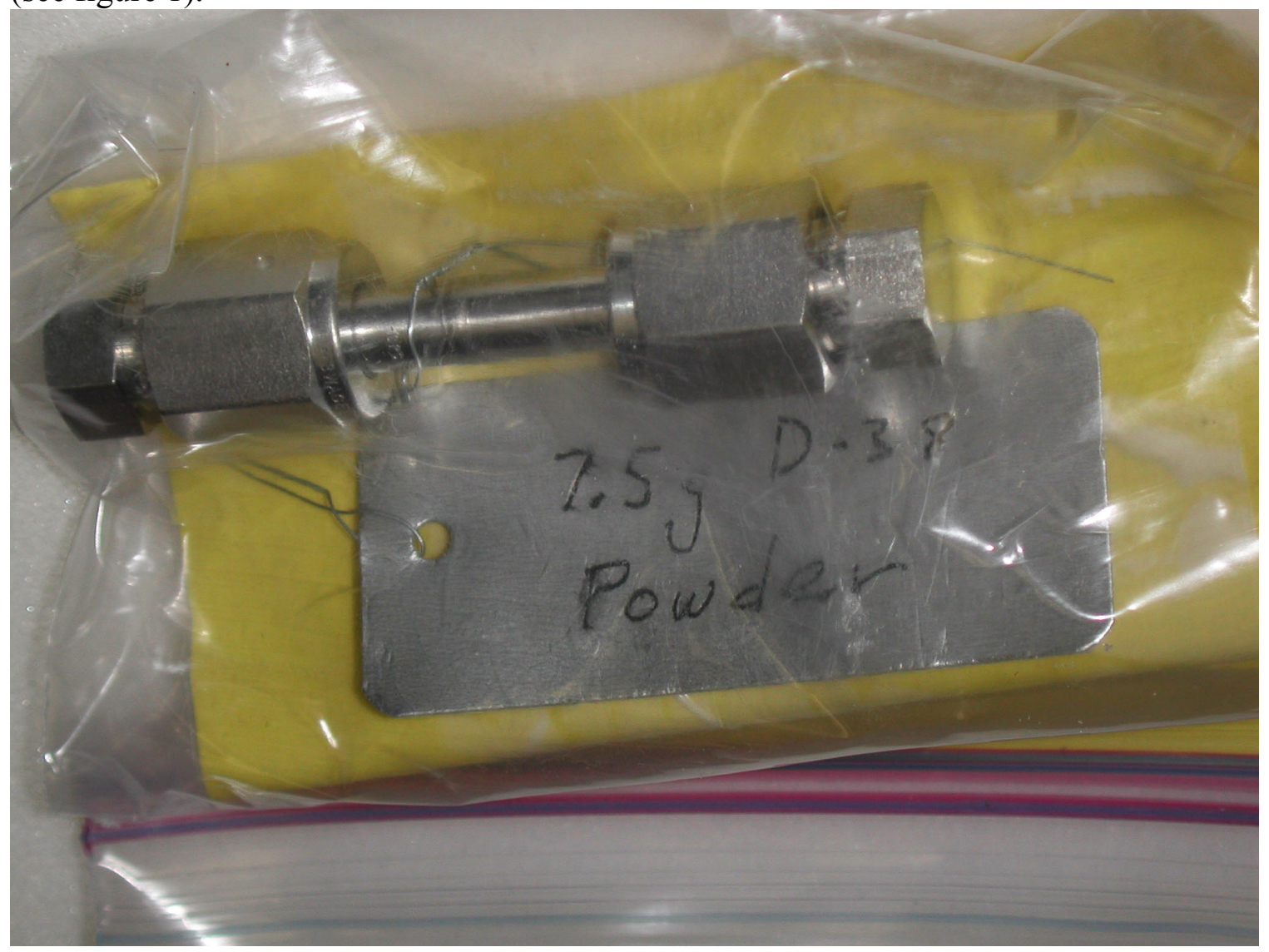

Figure 1. UHV - sealed shipping tube with uranium powder. 
A very small quantity of powder was transferred in a LLNL glove box to two SEM sample holders, labeled "powder \#1" and "powder \#2". The oxygen pressure in the glove box increased when the shipping tube was opened, implying that the tube was NOT held at a good glove box atmosphere.

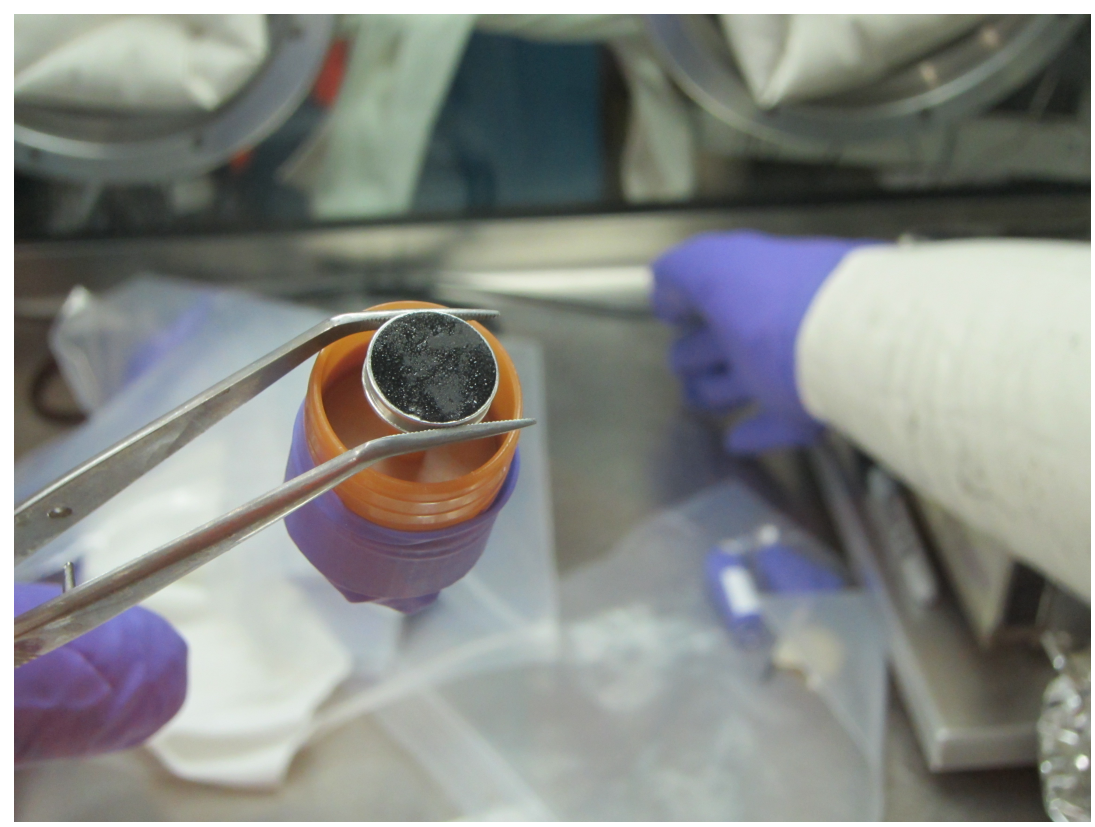

Figure 2. SEM "powder \#1" sample holder

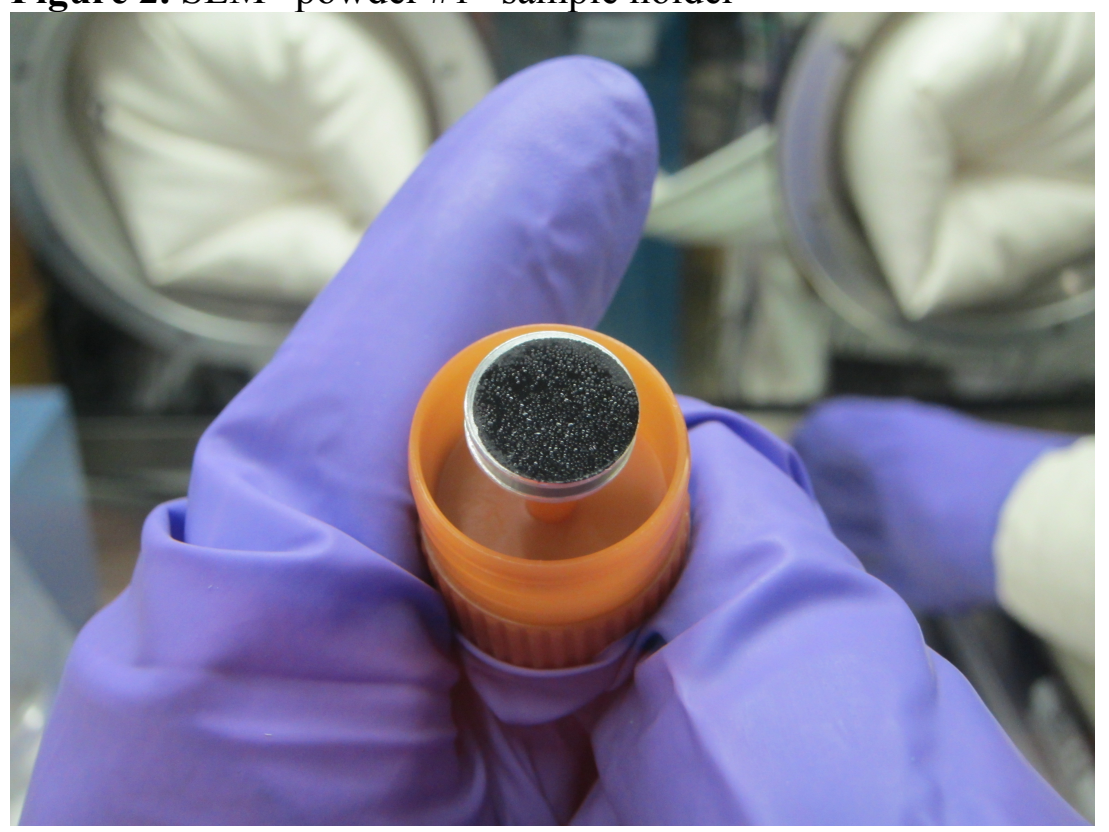

Figure 3. SEM “powder \#2" sample holder

SEM sample "powder \# 1" has areas with sparse particle density, while SEM sample "powder \# 2" has a high particle density everywhere. Both samples were kept in vacuum 
(dry vacuum fore pump) for about one day before SEM analysis. Both samples were imaged.

Figure 4 of "powder\#1" at a magnification of $650 \mathrm{x}$ documents that there is a broad distribution of particle sizes, starting at a few micrometers in diameter and ending at about 30 micrometer, with the majority of particles around about $15 \mu \mathrm{m}$ diameter. Uranium particles may acquire an oxide surface layer during production through reaction with oxidizing gas impurities. Since the particles have been exposed to a glove-box atmosphere for many years, that oxide layer will have grown. In addition, all oxide originally present in the parent material will segregate to the surface [1] while uranium is liquid.

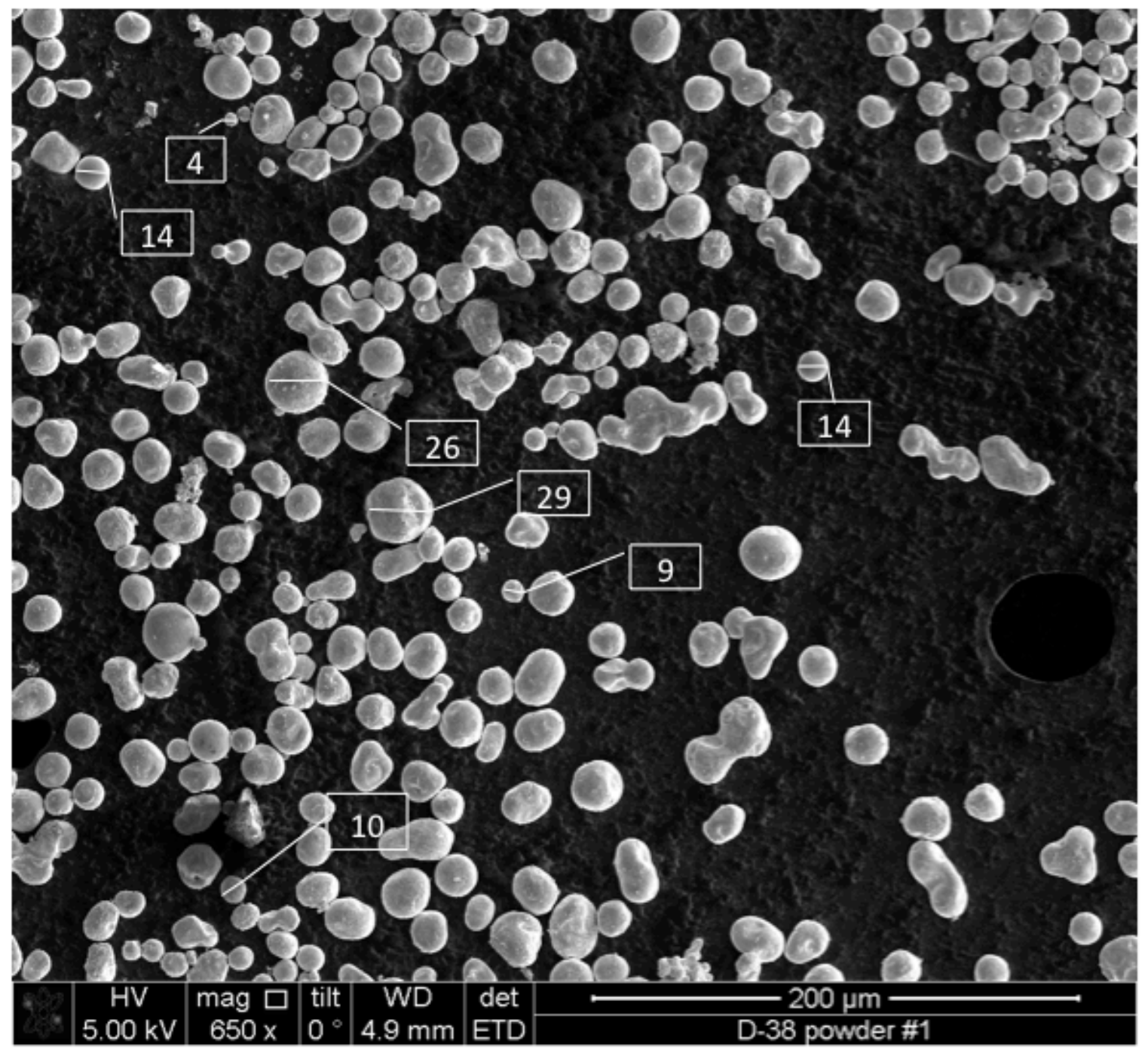

Figure 4. "Powder \# 1" at $650 \mathrm{x}$, top-view, 0 degree stage tilt, at a location with sparse particle density, the numbers in "rectangles" showing a range of particle sizes (in $\mu \mathrm{m}$ ).

[1] W. Mclean, and W. Siekhaus, J Less-Common Met 122 (1986). 
In both figure 4 and 5 it is evident that frequently particles agglomerate into "dumb-bell" shaped objects consisting of two or more originally round particles.

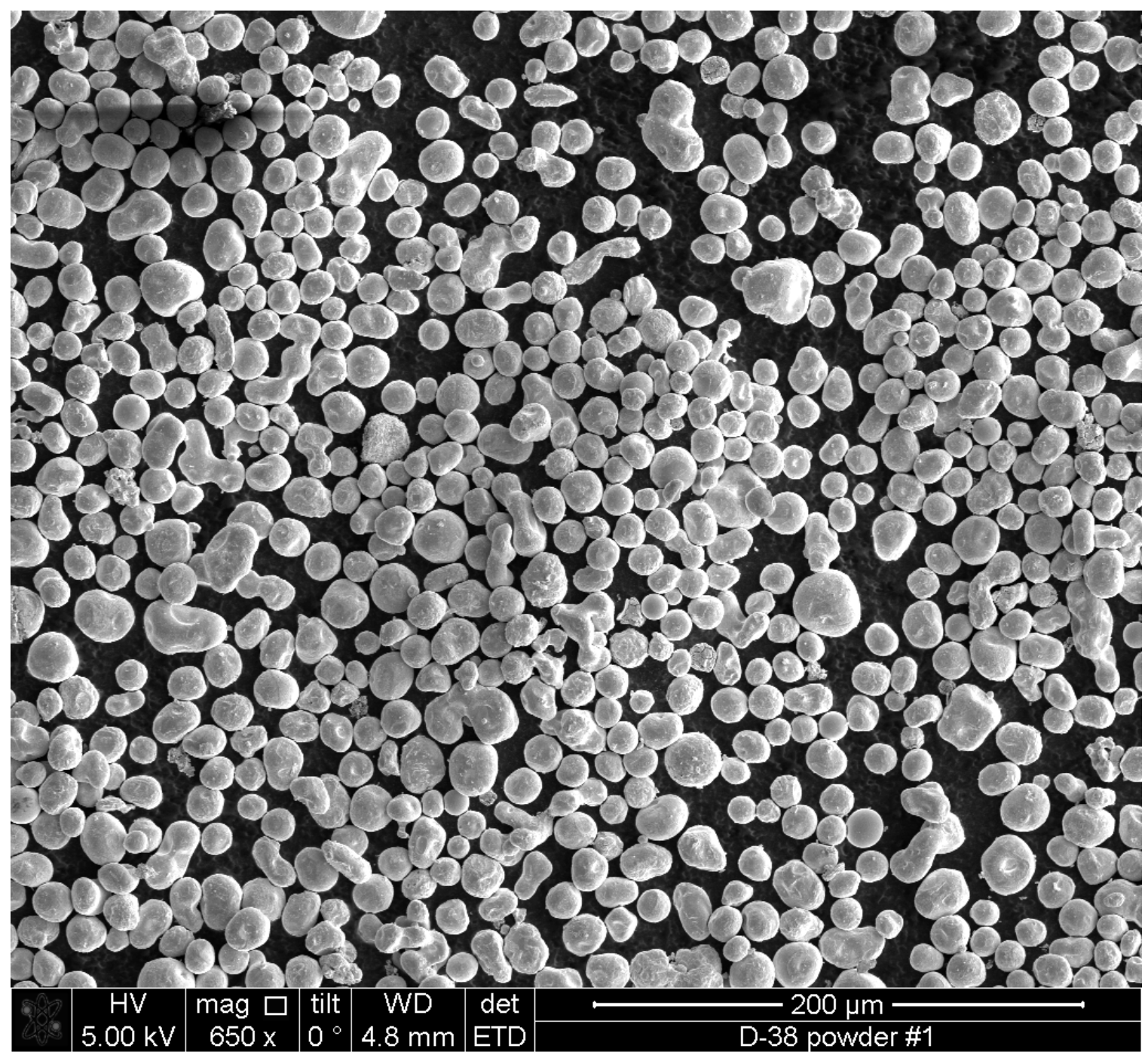

Figure 5. "Powder \# 1" at $650 \mathrm{x}$, top-view, 0 degree stage tilt, at a location with high particle density. The great majority of particles are in the 10-20 $\mu \mathrm{m}$ range. Larger particles appear often to be agglomerates of smaller particles. 


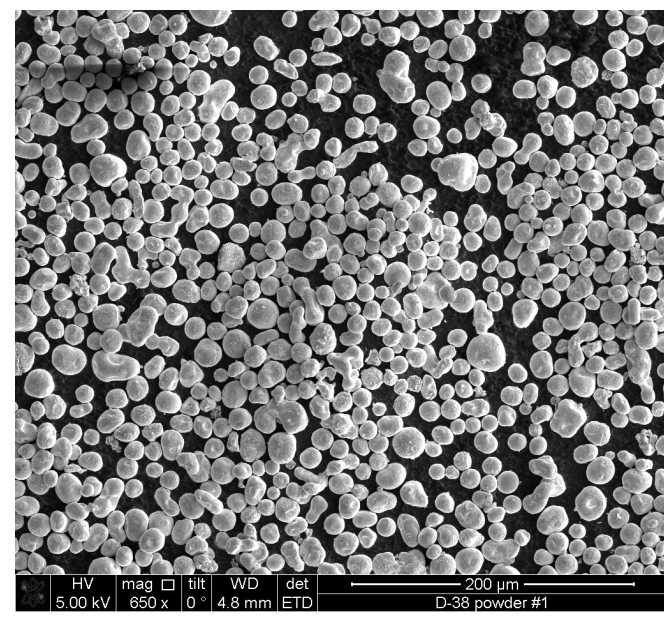

U powder, SEM image, Fig. 5 powder diameter data M. A. Wall, 8/1/13

\begin{tabular}{lc} 
Minimum & 3.4500 \\
Maximum & 48.510 \\
Sum & 4567.2 \\
Points & \multicolumn{2}{c}{280.00} \\
Mean & 16.311 \\
Median & 15.670 \\
RMS & 17.192 \\
Std Deviation $\quad 5.4413$ \\
Variance & 29.608 \\
Std Error & 0.32518
\end{tabular}

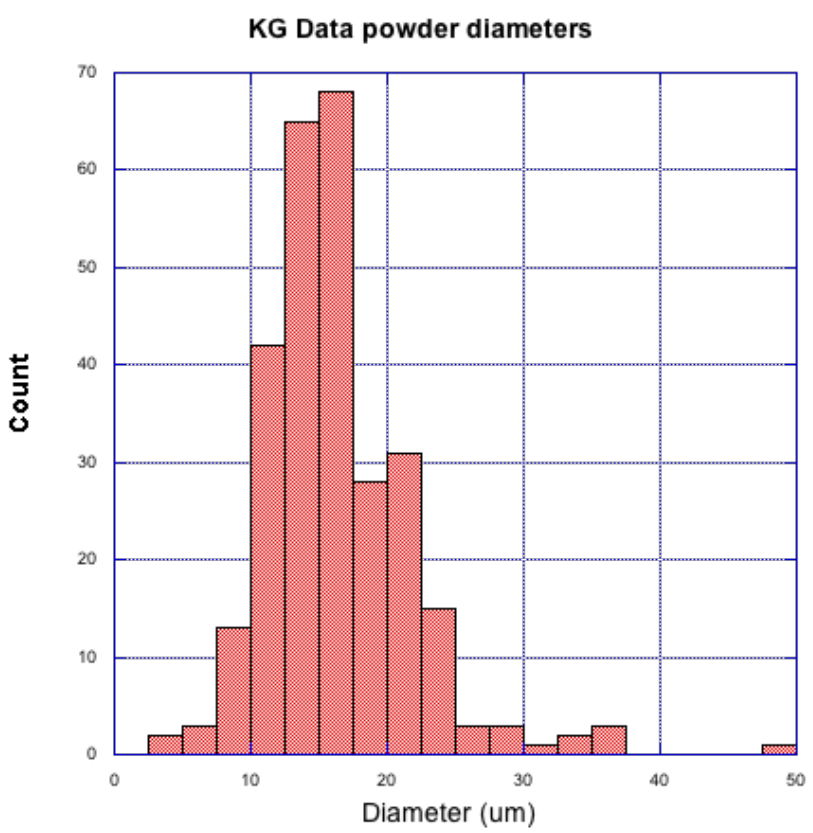

Figure 5 a. Measured size distribution of the particles in figure 5, confirming that the majority of the particles have diameters between 10 and 20 micrometers. Particle analysis courtesy of Mark Wall, LLNL. 


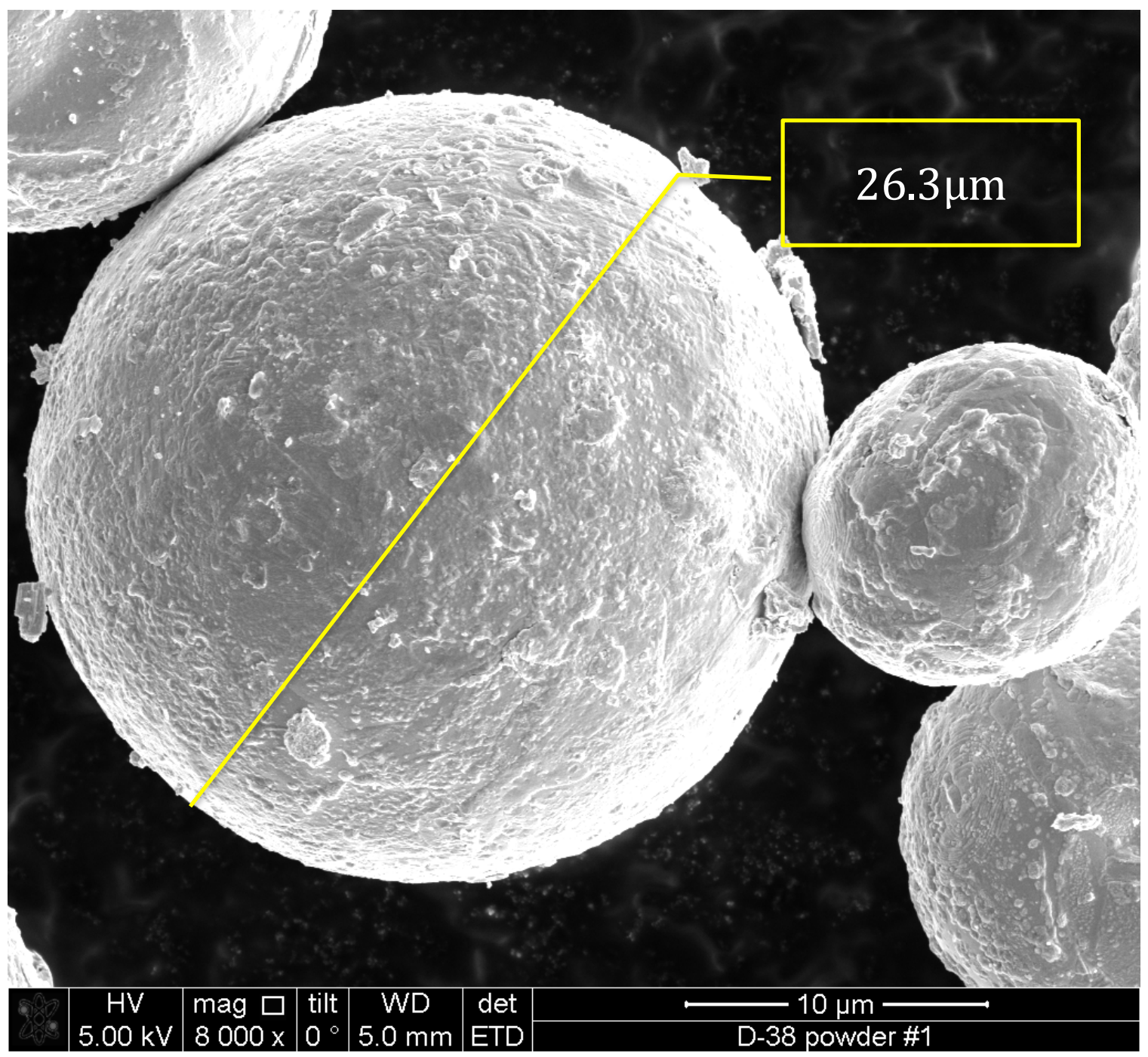

Figure 6. "Powder \# 1" at $8000 \mathrm{x}$, top-view, 0 degree stage tilt. Notice the roughness or "bumpiness" of the surface oxide. 


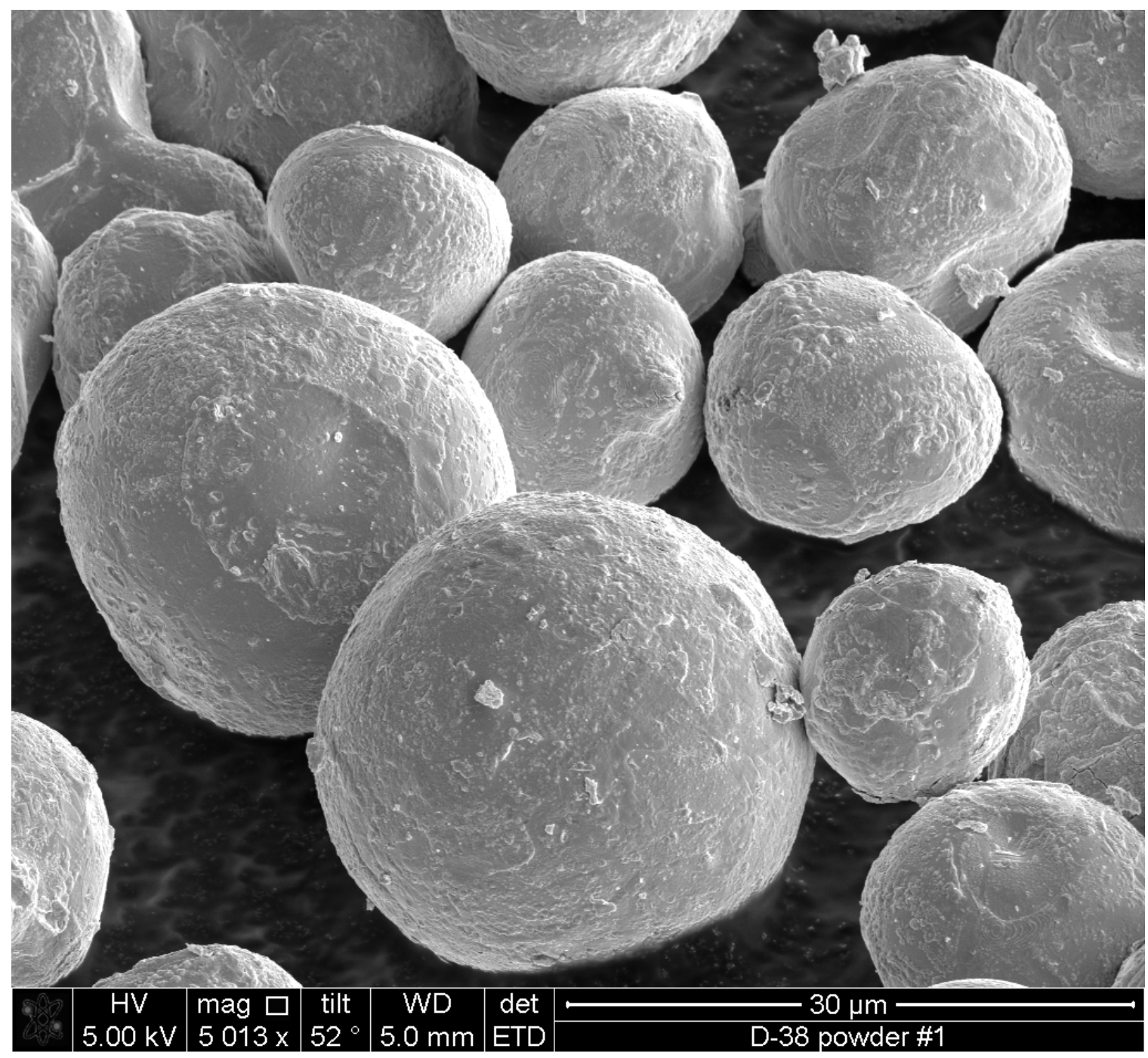

Figure 7. "Powder \# 1" at $5000 \mathrm{x}$, side-view, $52^{\circ}$ degree stage tilt, showing the variation in 3-D structure and surface roughness of the particles. 


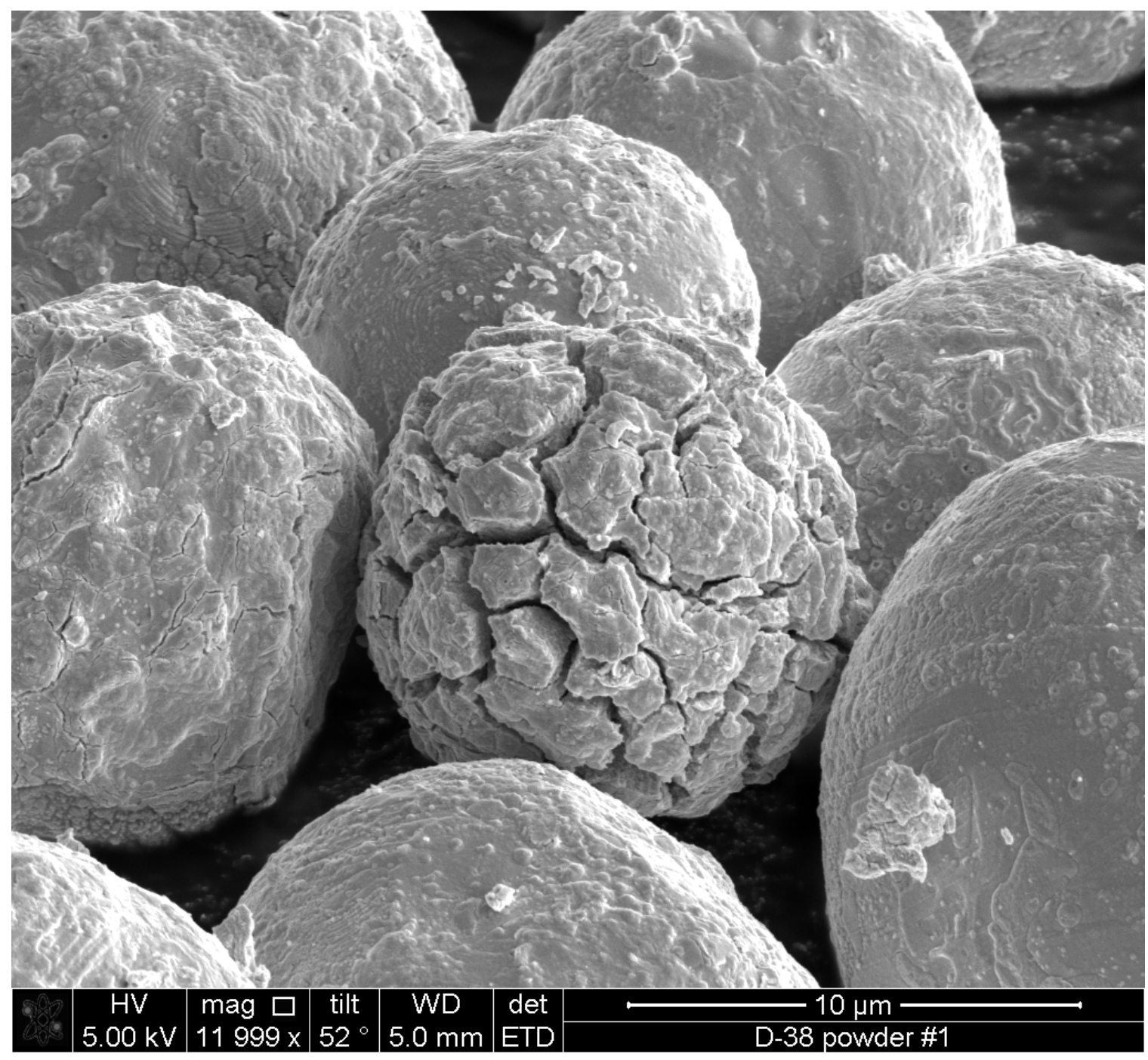

Figure 8. "Powder \# 1" at $12000 \mathrm{x}$, side-view, $52^{\circ}$ degree stage tilt, showing the variable 3 -D structure of the particles, the roughness of the oxide layer, and in the middle and upper left particles cracks in the oxide. The central particle is a very unusual one of unknown composition. Since it is round, the material of which it consists must have been liquid when it was formed. 


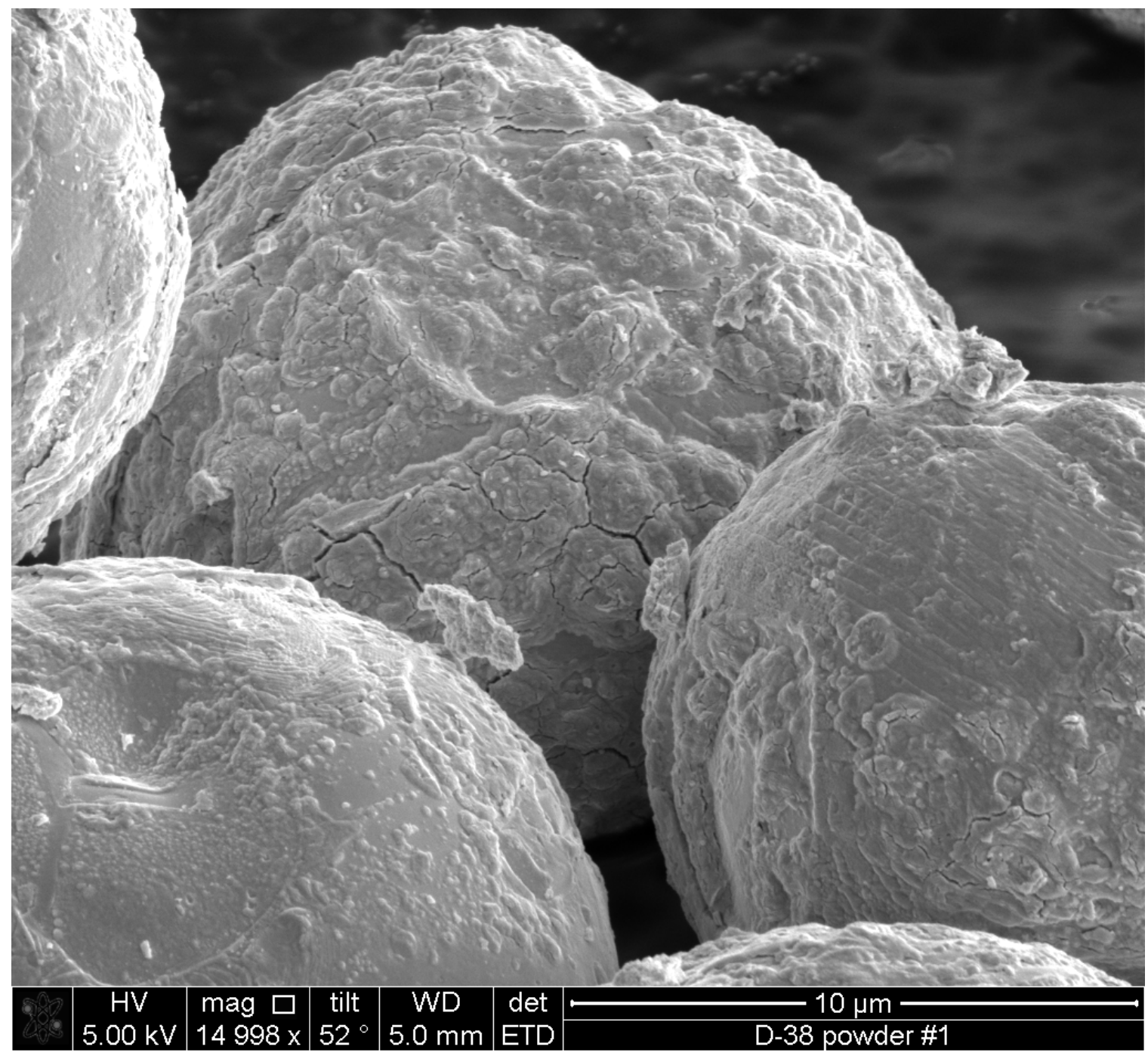

Figure 9. "Powder \# 1" at $15000 \mathrm{x}$, side-view, $52^{\circ}$ degree stage tilt, showing the variable 3 -D structure of the particles, and the roughness and "bumpiness" of the oxide layer. Cracks in the oxide layer are not rare. 


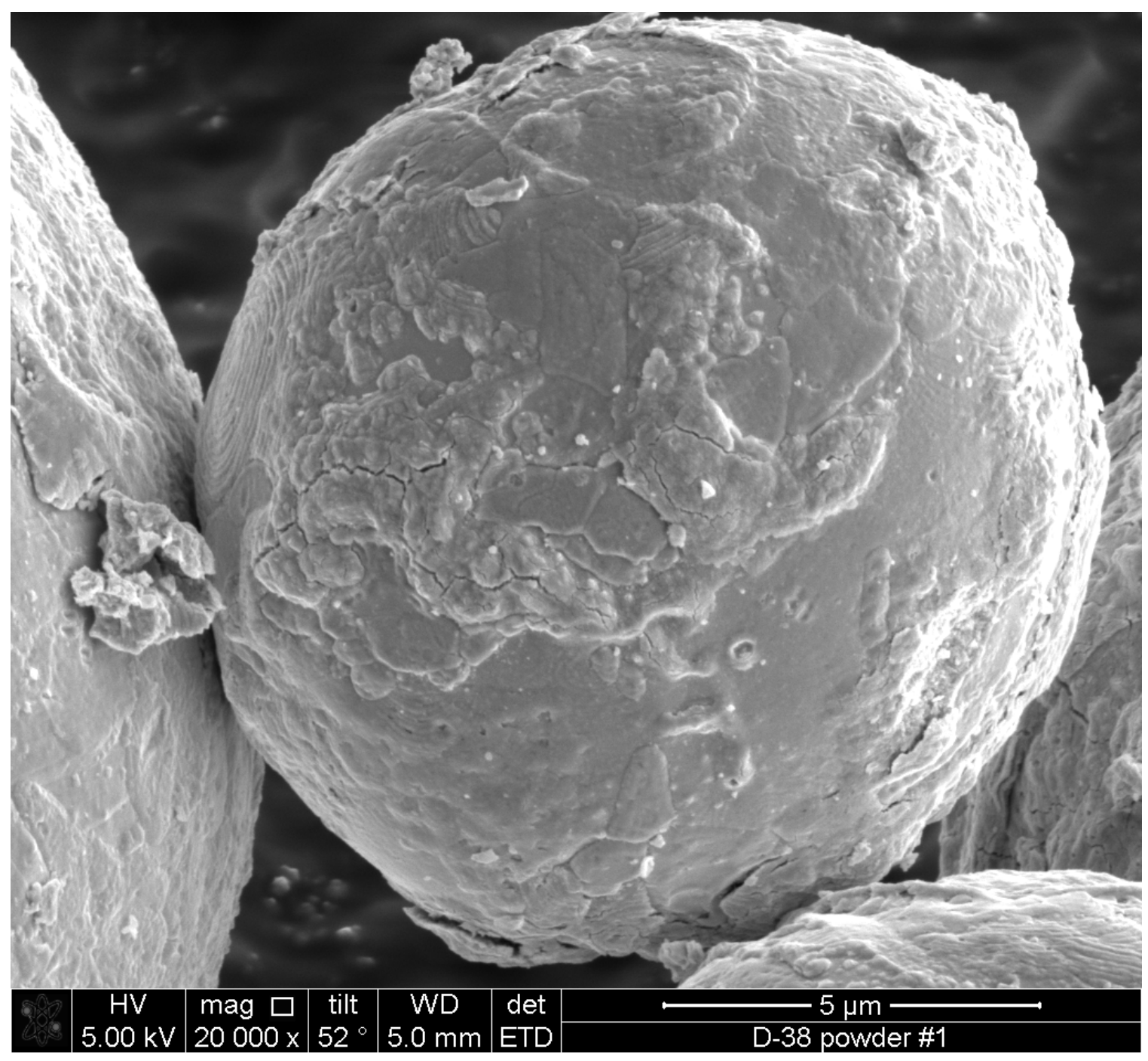

Figure 10. "Powder \# 1" at $20000 \mathrm{x}$, side-view, $52^{\circ}$ degree stage tilt, showing the roughness and "bumpiness" of the oxide layer. Cracks in the oxide layer are not rare. 


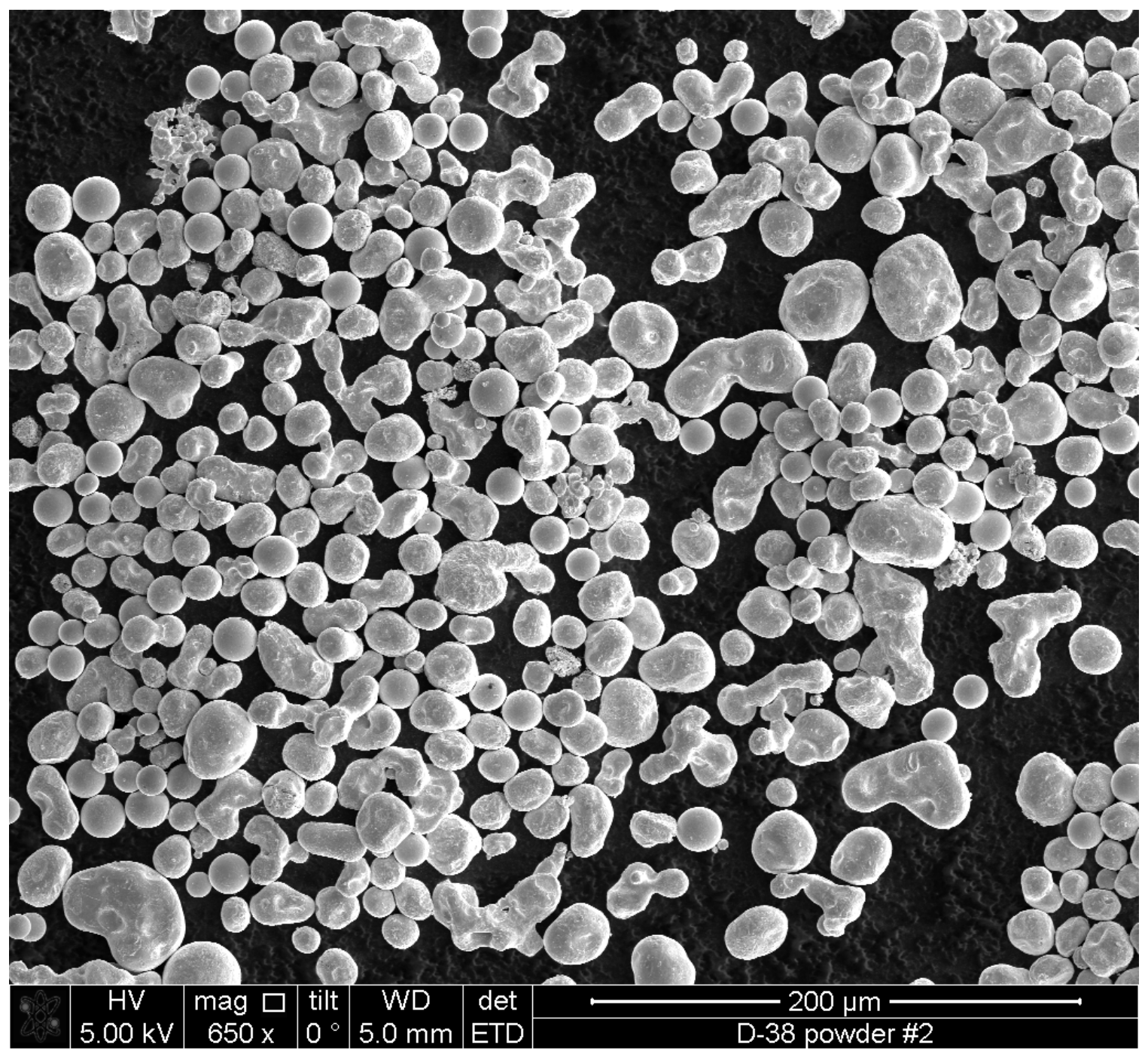

Figure 11. "Powder \# 2" at $650 \mathrm{x}$, top-view, 0 degree stage tilt, at a location with high particle density. The great majority of particles are in the 10-20 $\mu \mathrm{m}$ diameter range. Larger particles appear often to be agglomerates of smaller particles. 
To determine the "typical" thickness of the oxide layer a row of adjacent particles of different sizes and shapes was selected, and the stage was rotated to make the axis of that row parallel to the x-axis of SEM scans, as shown by the "red" outline in figure 12.

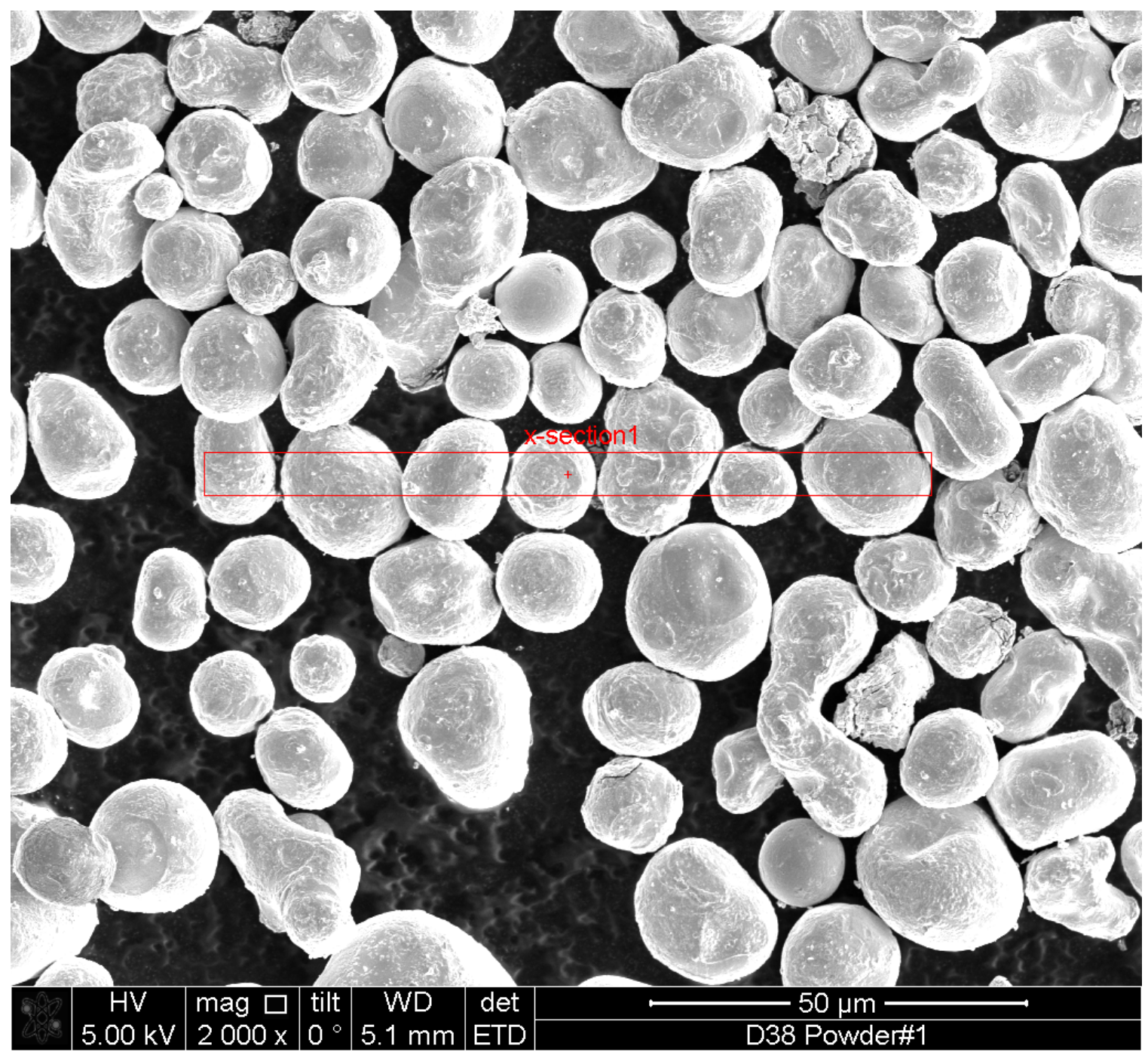

Figure 12. "Powder \# 1" at $2000 \mathrm{x}$, top-view, 0 degree stage tilt, at a location with high particle density. The row of particles in the area outlined in "red" will be sectioned by focused ion beam etching to determine the oxide thickness. 


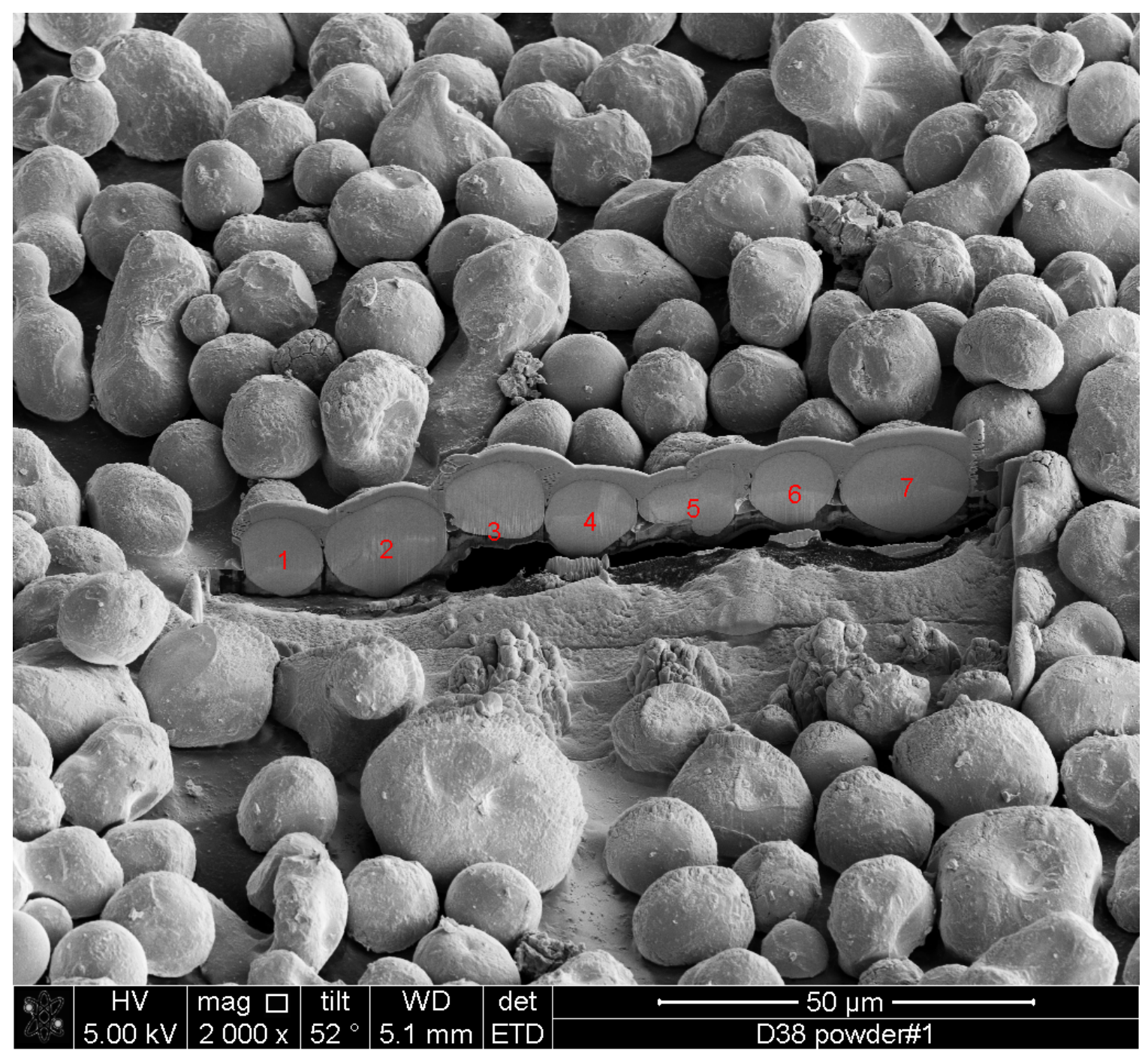

Figure 13. "Powder \# 1" at $2000 \mathrm{x}$, side-view, $52^{\circ}$ degree stage tilt, after depositing a thin layer of electron beam and ion beam deposited platinum over the row of particles (labeled here 1 to 7 ) and subsequent FIB sectioning. To see more detail, view the image at 300 to 500x in MS Word. When you go to higher magnification you will see on this image (and on the subsequent images of individual particles at higher magnification) that the large area high current FIB-sectioning done here across the 7 particles left FIB curtaining and some re-deposition artifacts from the FIB milling. That does NOT affect measurements of the oxide thickness. 


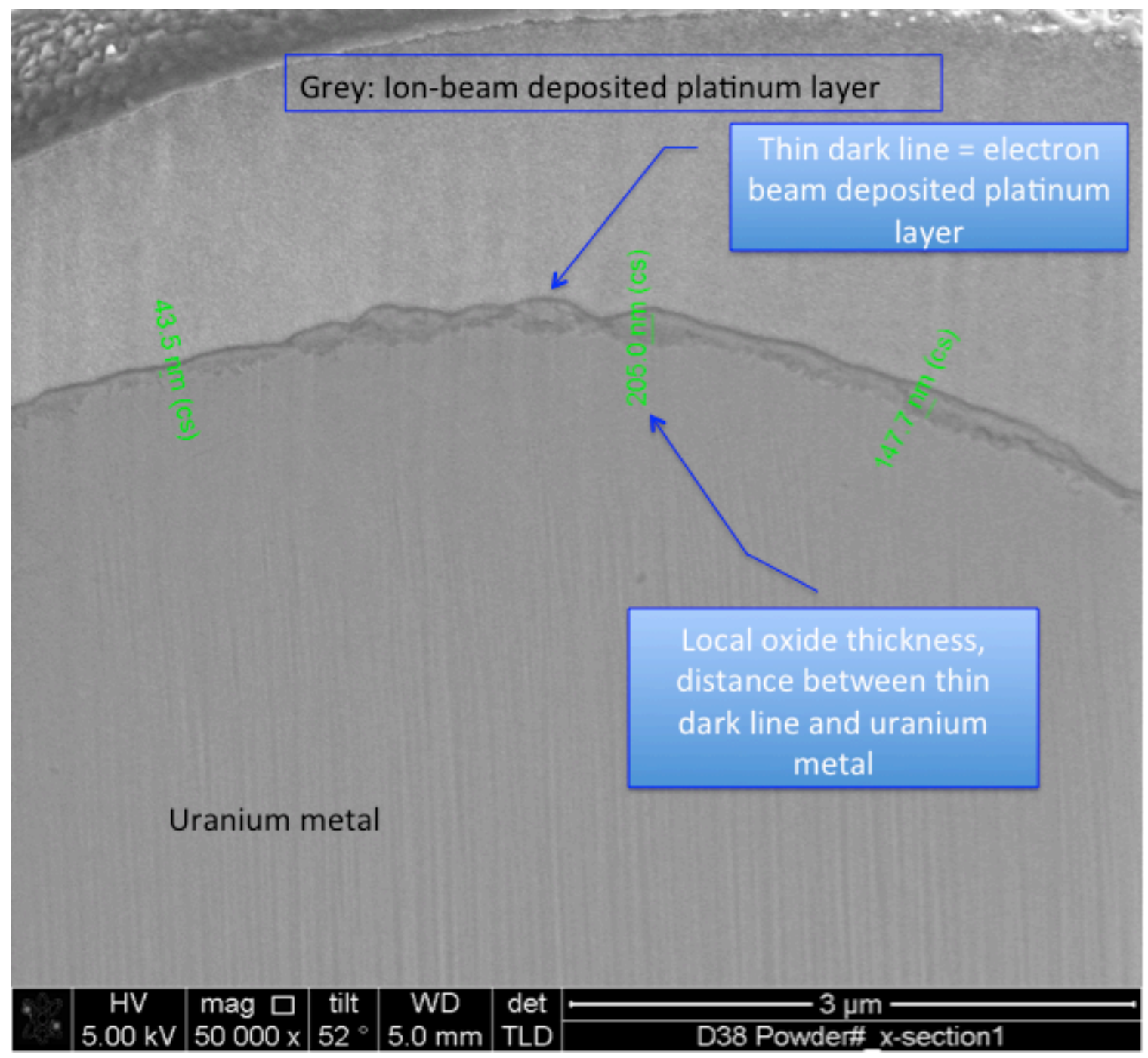

Figure 14. SEM image of particle number 1 of figure 13, x 50000, side-view, stage tilted at $52^{\circ}$ degree. The oxide thickness is measured as the distance between the dark electronbeam deposited platinum and the uranium metal. There are two types of oxide: 1) thin, $\sim 40 \mathrm{~nm}$, and 2) thick, up to $200 \mathrm{~nm}$. Increase the size of this image in MSWord to 300x to clearly see how the measurement was done. 


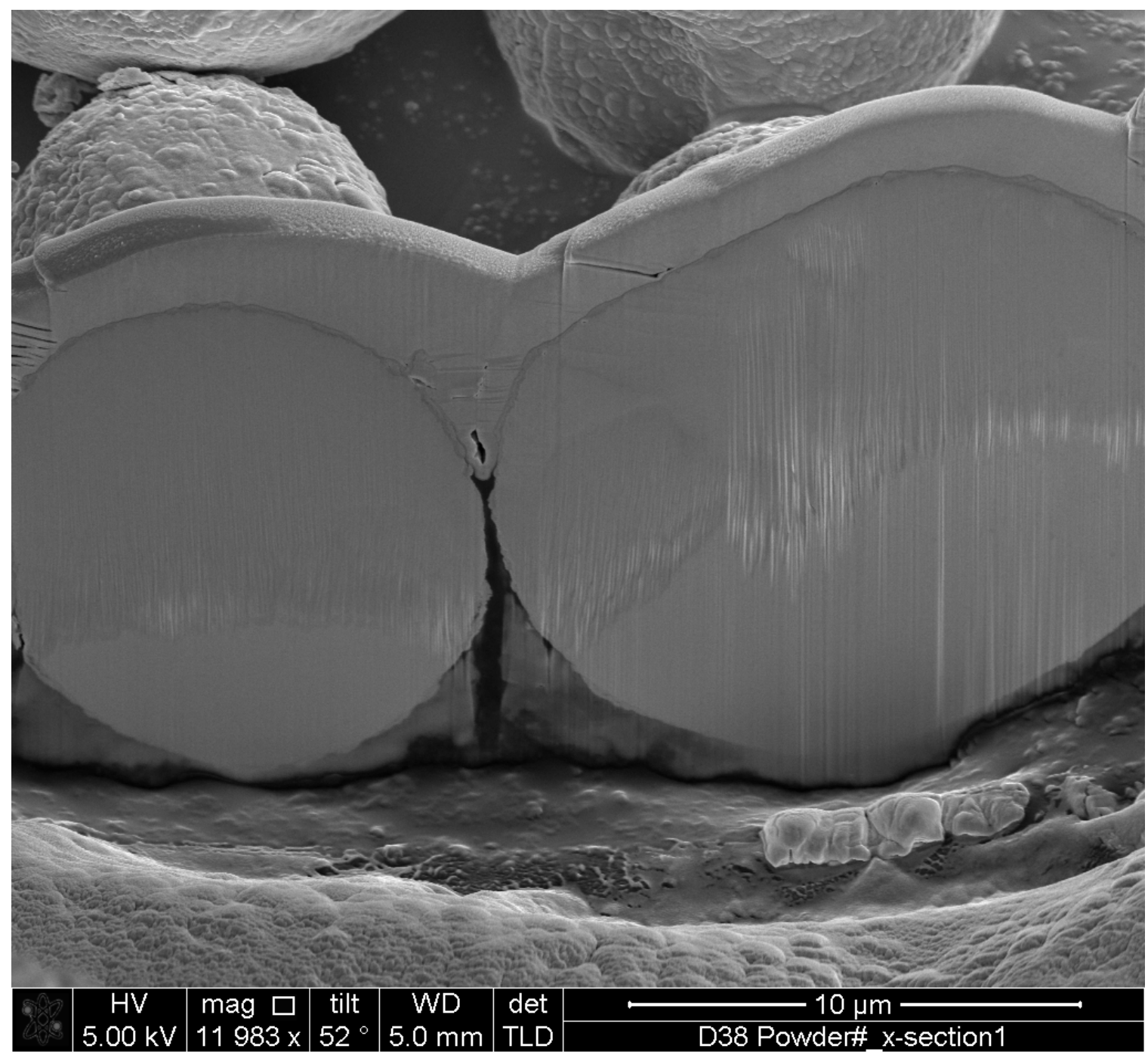

Figure 15. SEM image of particles number 1 and 2 of figure 13, x 12000, side-view, stage tilted at $52^{\circ}$ degree. The oxide thickness is the distance between the very thin dark line of the electron-beam deposited platinum and the uranium metal. Increase the size of this image in MSWORD up to 500x to clearly see the oxide. 


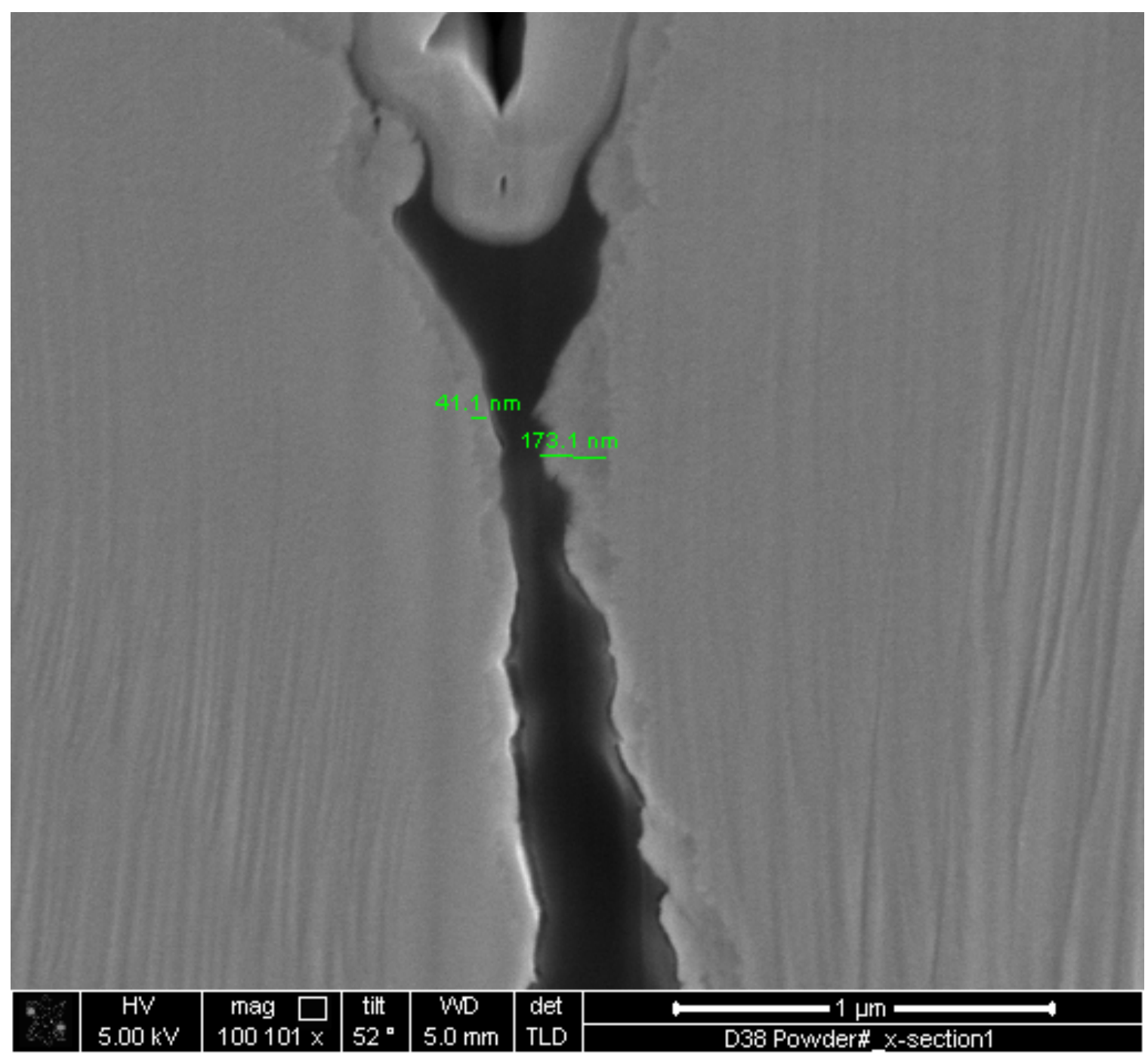

Figure 16. SEM image of the gap between particles number 1 and 2 of figure 13, $100000 \mathrm{X}$, side-view, stage tilted at $52^{\circ}$ degree. The $\mathrm{V}$-shaped item in the middle of the upper image is the end of the electron-beam and ion-beam deposited platinum. The lower part of the gap in the middle of the image is not reached by either electron or ion beam deposited platinum. In the lower part the oxide layer is visible through a slight contrast to the metal, and measured. You see again the variation in the thickness of the oxide layer, from about $40 \mathrm{~nm}$ to about $200 \mathrm{~nm}$. Increase the size of this image in MSWORD up to $500 x$ to clearly see how the measurement was done. 


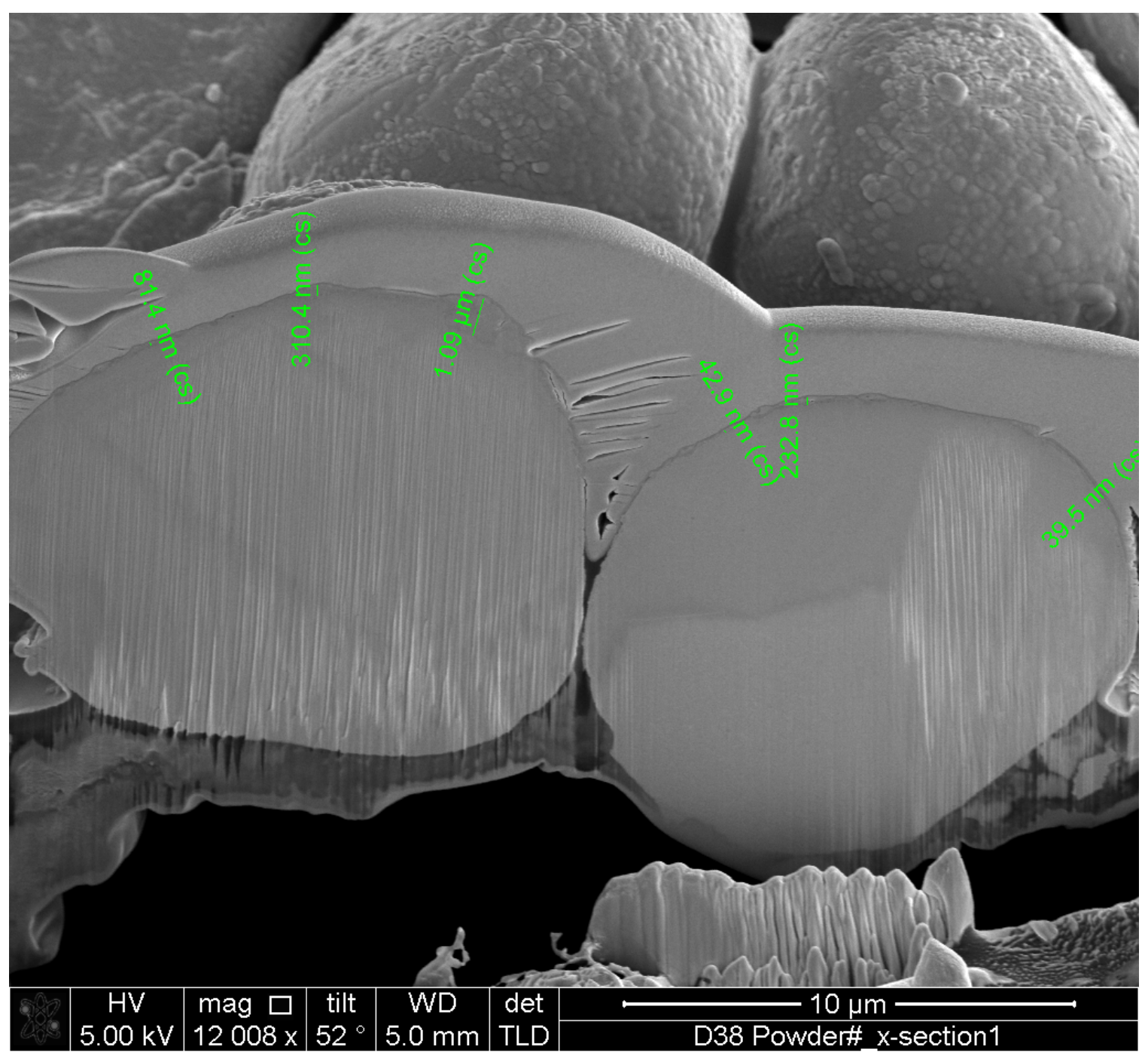

Figure 17. SEM image of particles number 3 and 4 of figure 13, x 12000, side-view, stage tilted at $52^{\circ}$ degree. The oxide thickness is measured as the distance between the electron-beam deposited platinum and the uranium metal. Increase the size of this image in MSWORD up to 500x to clearly see how the measurement was done. Non-uniform ion etching causes striations in the sectioned uranium. 


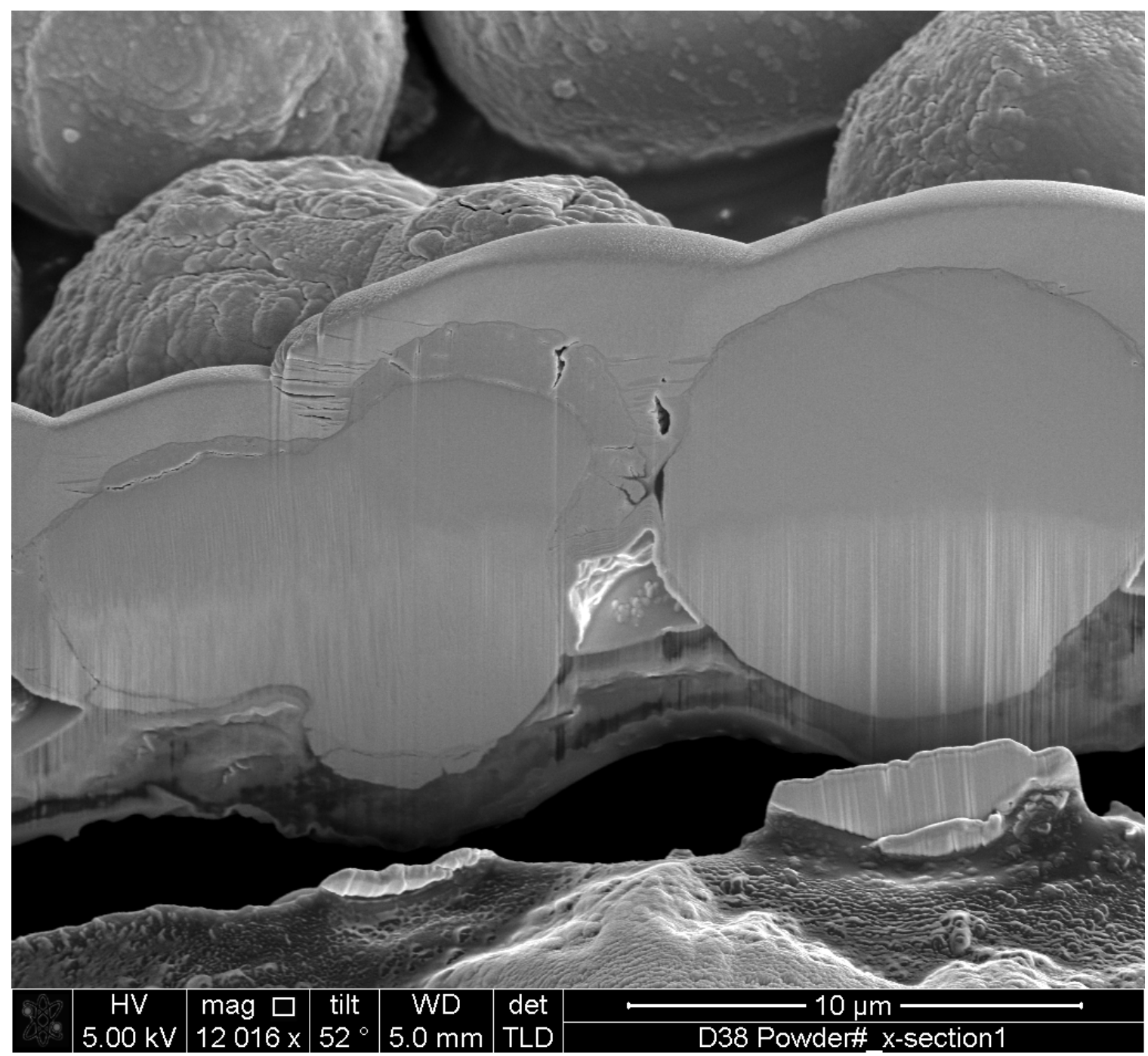

Figure 18. SEM image of particles number 5 and 6 of figure 13, x 12000, side-view, stage tilted at $52^{\circ}$ degree. The oxide thickness is measured as the distance between the very thin dark line of the electron-beam deposited platinum and the uranium metal. Increase the size of this image in MSWORD up to 500x to clearly see the oxide. It is apparent that particle 5 is an agglomerate of several particles. 


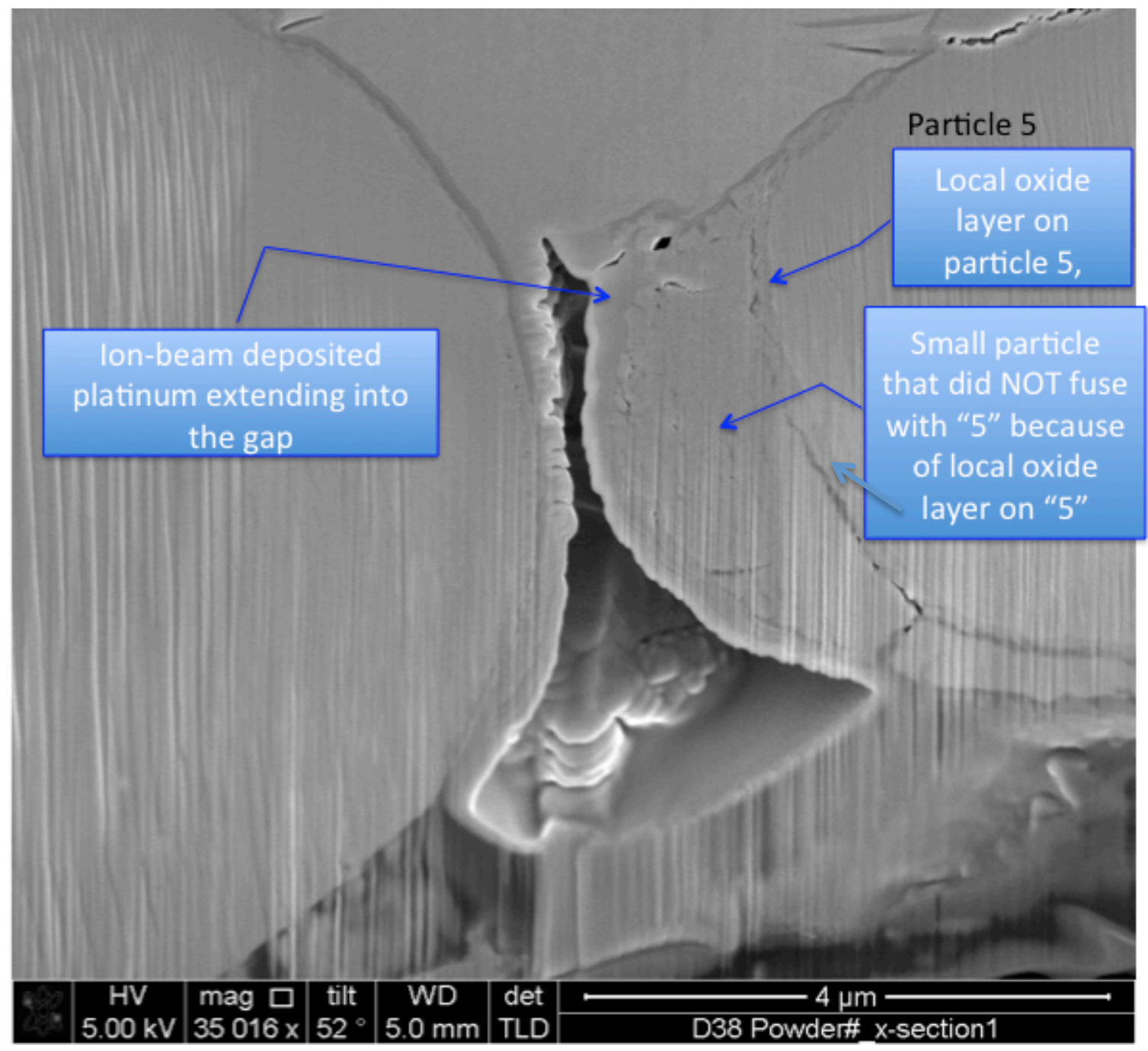

Figure 19. SEM image of the gap between particles number 4and 5 of figure 13, $\mathrm{x} 35000$, side-view, stage tilted at $52^{\circ}$ degree. The oxide thickness is measured as the distance between the very thin dark line of the electron-beam deposited platinum and the uranium metal. Increase the size of this image in MSWORD up to 500x to clearly see the oxide. It is apparent that particle 5 is an agglomerate of several particles. 


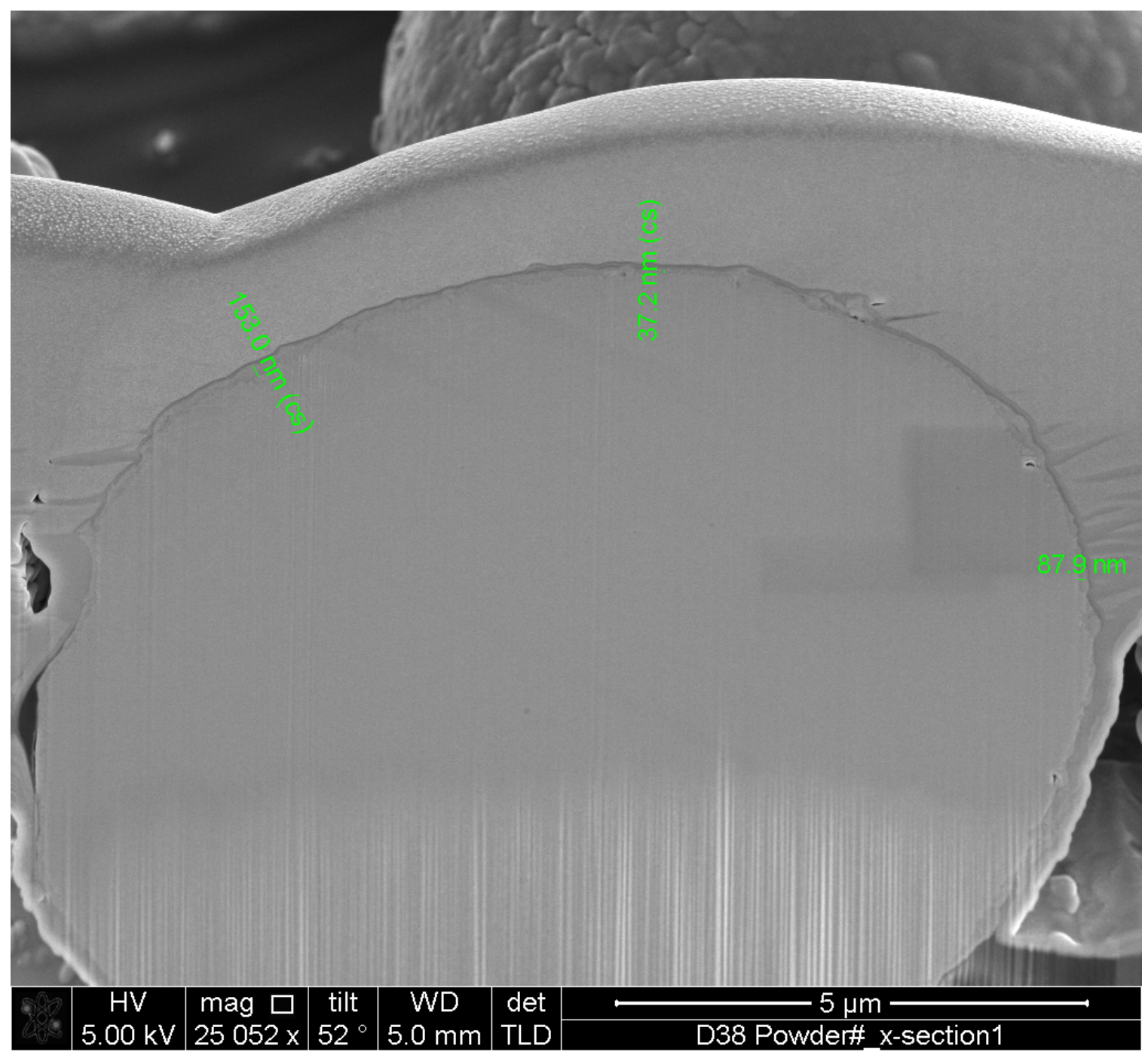

Figure 20. SEM image of particle number 6 of figure 13, x 25000, side-view, stage tilted at $52^{\circ}$ degree. The oxide thickness is measured as the distance between the very thin dark line of the electron-beam deposited platinum and the uranium metal. Increase the size of this image in MSWORD up to 500x to clearly see the oxide. 


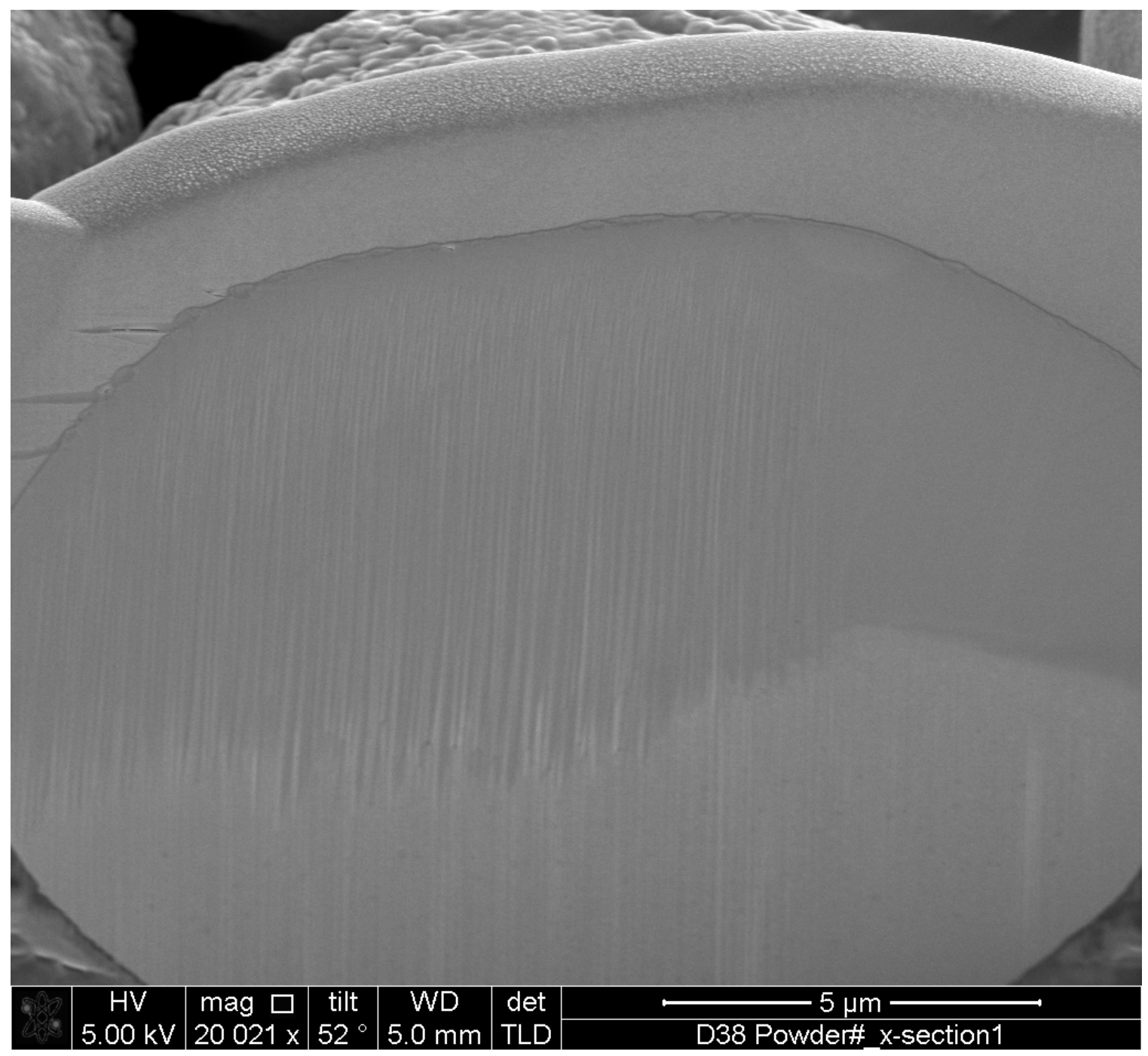

Figure 21. SEM image of particle number 7 of figure 13, x 20000, side-view, stage tilted at $52^{\circ}$ degree. The oxide thickness is measured as the distance between the very thin dark line of the electron-beam deposited platinum and the uranium metal. Increase the size of this image in MSWORD up to 500x to clearly see the oxide 


\section{Discussion}

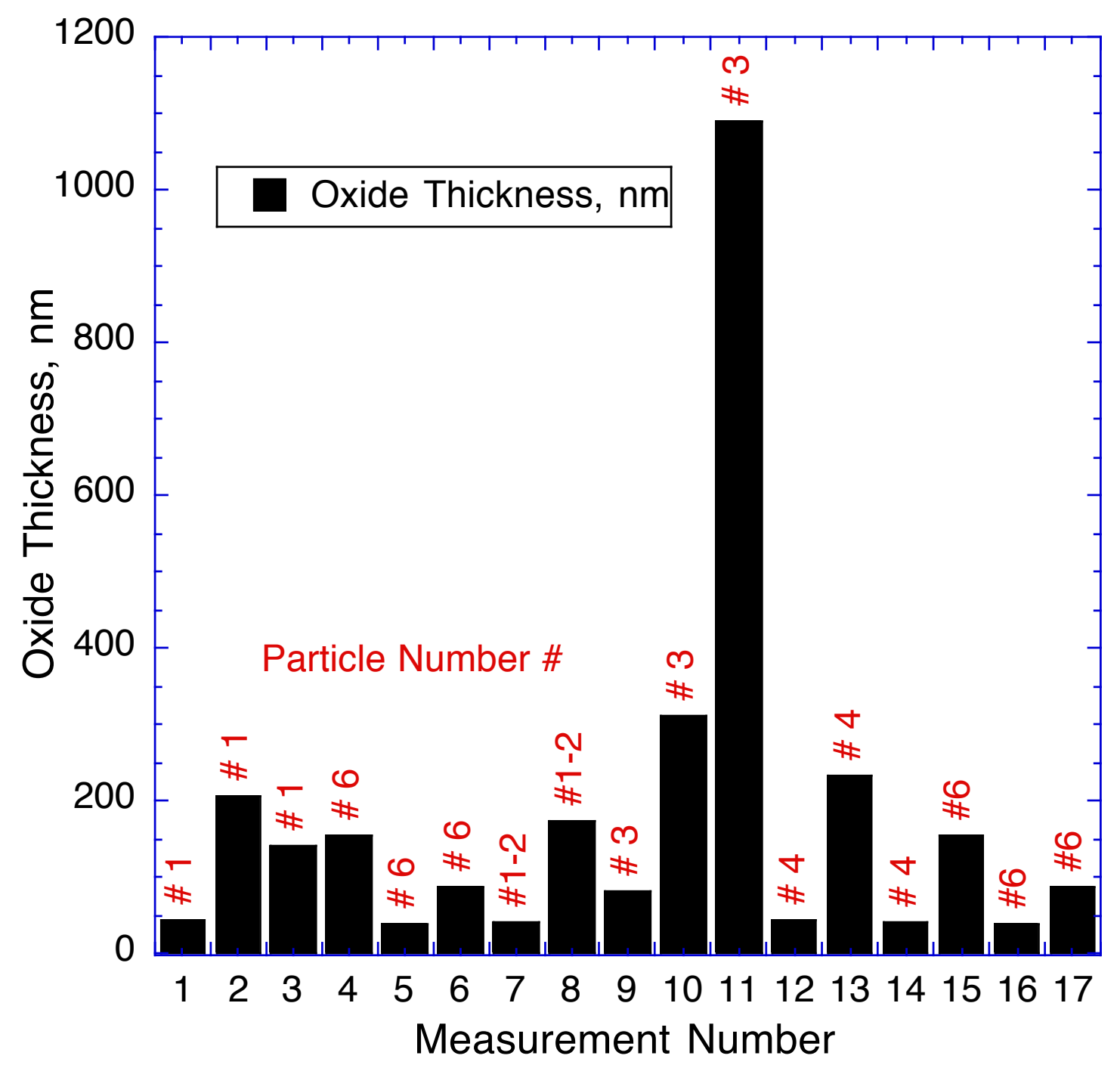

Figure 22. Measured oxide thicknesses on sectioned particles. There are clearly three classes of thicknesses: 1) measurements number 1,5,7,12,14,16 with a mean thickness of $40.23 \mathrm{~nm}, 2$ ) measurements $2,3,4,6,8,9,10,13,15,17$ with a mean thickness of 202.83 $\mathrm{nm}$, and 3) measurement 11 with a thickness of $1090 \mathrm{~nm}$.

Figure 22 shows the measured oxide thicknesses. The majority of the surface is covered with an oxide thickness of "class 1)" with an oxide thickness of about $40 \mathrm{~nm}$. Using oxide growth rates measured by G. L. Powell, (see figure 23 below), that corresponds to an oxide thickness grown in about 25 days at $22{ }^{\circ} \mathrm{C}$. I believe that this thickness represents the sum of the oxide thickness formed during production of the spheres and during the exposure over more than 20 years to an oxidizing atmosphere. According to 
Powell's formula, the oxide thickness of $40 \mathrm{~nm}$ is equivalent to 25 years at $760 *(1 / 365)$ Torr. As mentioned in the experimental section, an increase in oxygen was seen in the LLNL glove box when the UHV shipping tube was opened.

U 238 Oxide growth in laboratory air = high flux @ $13^{\circ} \mathrm{C}$ ( Powell,

\section{L.G.) measured by IR scattering spectroscopy (DRIFT)}

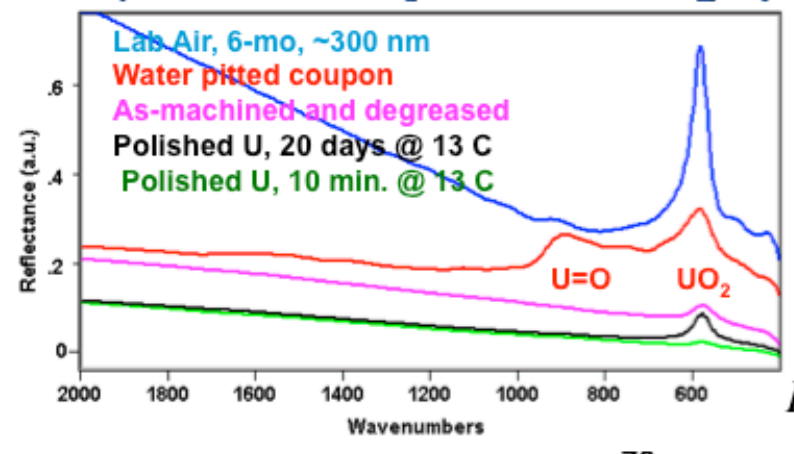

Infrared spectra carry film thickness, oxide stoichiometry, and organic contamination information.

Oxide thickness $(\mathrm{nm})=$ $1.935+6.766( \pm 1)^{*} \sqrt{ }$ day * $\left.\mathrm{e}^{(6500 / 8.31)([1 /(13+273)]-1 / \mathrm{T})}\right)$

Oxide thickness $(\mathrm{nm}) @ 13^{\circ} \mathrm{C}$ $=\sim 1.935+6.766( \pm 1)^{\star} \sqrt{ }$ day

$(\mathrm{R}=.99756)$

FTIRS light is p-polarized and reflected from the $\mathrm{U}$ at $75^{\circ}$ to the surface normal at the focal point.

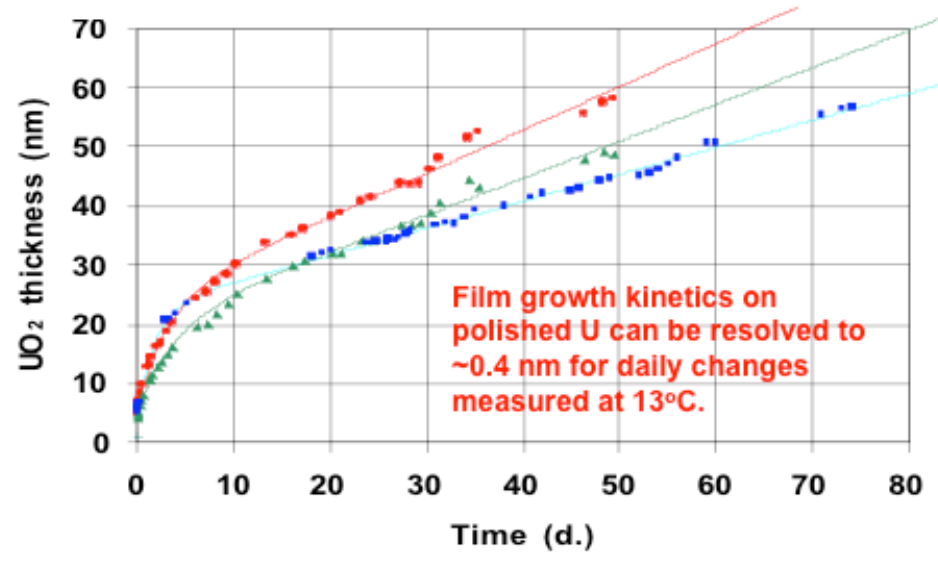

Figure 23. G. L. Powell's measurement of the uranium oxide growth rate in air with about $50 \%$ relative humidity.

The second class of oxide thicknesses associated with localized "blisters" (see the measurements on the sections of particles \# $1,3,4,6$ ). These blisters may represent sites where uranium oxidation did NOT form a oxide layer with low oxygen diffusivity, or alternately they are locations where oxide from the parent material segregated to the surface and aggregated on a particular spot on the liquid drop's surface, as seen in the bright spot in figure 24 (from reference [1]). 


\section{Low flux reaction of $\mathrm{H}_{2} \mathrm{O}$ and $\mathrm{O}_{2}$ with liquid $U^{2}$ \\ W. McLean, and W. Siekhaus, J Less-Common Met 122 (1986).}

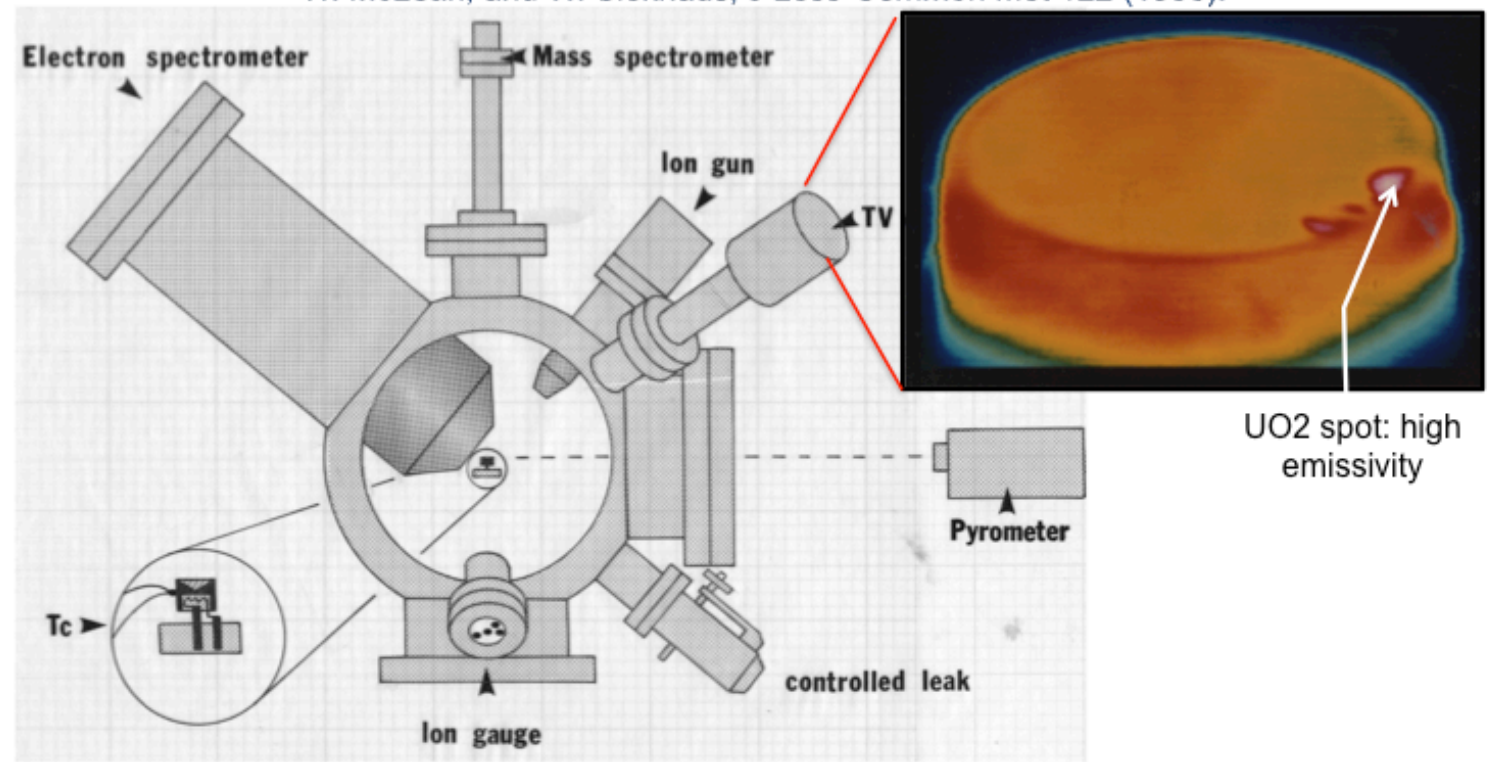

Oxygen solubility in $U$ at the melting point by Auger Spectroscopy $X_{0}^{b_{0}}:<10^{-4}$

Oxygen surface segregation coefficient at the melting point : $\beta_{0}^{S_{0}}:>10^{3}$

Figure 24. Aggregation of uranium oxide on a liquid uranium surface into a spot of high emissivity.

Class 3), i.e. oxides with $\mu \mathrm{m}$ thickness are clearly not the consequence of oxide growth from reactions with gas during the particle's storage time, but rather $\mathrm{UO}_{2}$ aggregates that attached themselves to the particles during the forming process.

This division into three classes of oxides seen in the cross sections is consistent with what is seen in figures $7,8,9,10$. The surfaces there are very bumpy, the oxide layer thickness is variable, just as the measurements on particles 1 to 7 of figure 13 and the statistic in figure 22 demonstrate.

One can imagine that the smooth areas in figure 10 represent the $\sim 40 \mathrm{~nm}$ thick oxide, that the patches, some with cracks, represent the thicker, $\sim 80 \mathrm{~nm}$ items in figure 22 . One can further rationalize that a "bump" on the left particle in figure 13 (just above the loose piece of oxide between the particles) is a spot where the oxide has $\mu \mathrm{m}$-scale thickness. 


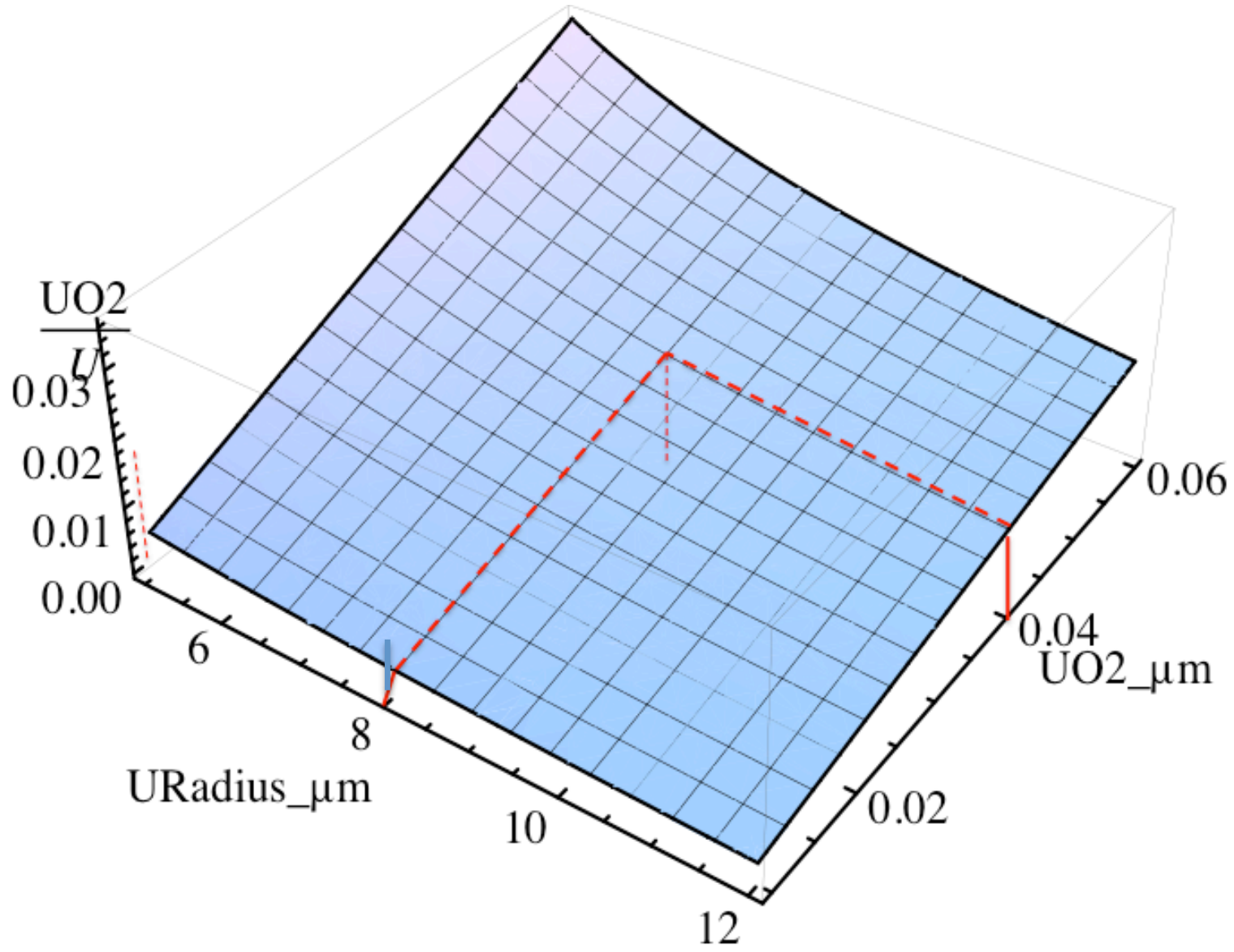

Figure 25. The ratio of the $\mathrm{UO}_{2}$ volume to the $\mathrm{U}$ volume as a function of particle radius and oxide thickness, the latter two measured in $\mu \mathrm{m}$.

Material formed from this powder would have a high content of $\mathrm{UO}_{2}$. Figure 25 plots the ratio of the $\mathrm{UO}_{2}$ volume to the $\mathrm{U}$ volume in a sample made from oxidized powder as a function of particle radius and oxide thickness, the latter two measured in $\mu \mathrm{m}$. Figure 25 shows that material formed from particles with a radius of $8 \mu \mathrm{m}$ and an oxide thickness of $40 \mathrm{~nm}$ the oxide would occupy close to 2 percent of the material.

\section{References}

[1] W. Mclean, and W. Siekhaus, J Less-Common Met 122 (1986).

\section{Acknowledgements}

to Dione Ancheta, LLNL, for transferring the uranium powder in a glove box from the stainless steel shipping tube to the SEM sample holders. 